\title{
A prática de alfabetização em Informação e Comunicação em Saúde: o olhar dos agentes comunitários de Saúde
} sobre o projeto de Inclusão Digital em Sergipe, Brasil

\author{
Pablo Boaventura Sales Paixão' \\ Valéria Pinto Freire ${ }^{2}$ \\ Maria de Fátima Monte Lima ${ }^{3}$ \\ Ronaldo Nunes Linhares ${ }^{4}$ \\ Ana Valéria Machado Mendonça ${ }^{5}$ \\ Maria Fátima Sousa ${ }^{6}$
}

\section{Introdução}

No Brasil, o Programa Sociedade da Informação (Socinfo) é considerado, sob a ótica do Estado, um marco para a implantação de políticas de inclusão digital. Em dezembro de 2000, o Programa, por meio do Ministério de Ciência e Tecnologia (MCT), produziu o 'Livro Verde', traduzindo as políticas públicas na área. Mapeou e identificou as ações de universalização das TIC, para os integrantes de comunidades em risco social, tais como: o investimento em pesquisa e desenvolvimento de novas tecnologias; a promoção da informatização da administração pública e do uso de padrões nos seus sistemas aplicativos; a implantação de infraestrutura básica nacional de informações, dentre outras (Brasil, 2000).

As políticas de universalização das TIC implementadas, no Brasil, no limiar do século XXI (Lima, 2007), imprimiram urgência na realização de projetos, para os indivíduos, como forma de incluí-los na cultura digital, para além da disponibilização de aparatos tecnológicos. Nesse sentido, incluir digitalmente deve centrar-se na formação de sujeitos ativos, construtores de novos conhecimentos e produtores de informação, e não, simplesmente, a acessibilidade às TIC. Assim entendida, a inclusão digital significa 'infoinclusão social', garantia de acessibilidade e conectividade à Socinfo, a partir das inovações midiáticas em TIC, para além das habilidades e do domínio técnico, e que possibilite o fortalecimento do cidadão para o "agir comunicativo" consciente (Habermas, 2001), a partir de práticas de educação dialógica e emancipatória (Freire, 1979) envolvendo todos os níveis de inclusão digital (Sorj, 2003).

A percepção de que os sujeitos deveriam ser incluídos num mundo novo, ser alfabetizados para utilizarem as TIC, ampliando sua condição de cidadãos na Socinfo, passou a ser uma constante nos programas e ações de governo, nos mais diversos campos, com atenção especial na Formação Continuada de profissionais nas áreas da educação e da saúde.

Considerando a oportunidade e amplitude das ações do Programa Nacional de Agentes Comunitários de Saúde, este artigo teve como objetivo verificar como um grupo de ACS sergipanos, integrantes do Projeto de Inclusão Digital de Agentes Comunitários de Saúde de Sergipe ${ }^{7}$, analisam as práticas de Alfabetização em Informação e Comunicação (ALFIN) desenvolvidas pelo mesmo, identificando dificuldades e facilidades destes sujeitos com o uso das TIC.

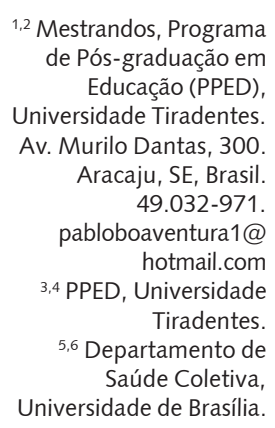

1,2 Mestrandos, Programa de Pós-graduação em Educação (PPED), Universidade Tiradentes. Av. Murilo Dantas, 300. Aracaju, SE, Brasil. 49.032-971. pabloboaventura1@ hotmail.com ${ }^{3,4}$ PPED, Universidade Tiradentes.

5,6 Departamento de Saúde Coletiva, Universidade de Brasília.

\footnotetext{
${ }^{7}$ Este Projeto foi desenvolvido pelas Unidades de Tecnologias da Informação e Comunicação em Saúde (UTICS) e de Estudos e Pesquisas em Saúde da Família (UEPSF), do Núcleo de Estudos em Saúde Pública (NESP), do Centro de Estudos Avançados Multidisciplinares (CEAM), da Universidade de Brasília (UnB), em parceria com a

Universidade Tiradentes (UNIT), para as ações no Estado de Sergipe. Tratase de iniciativa de inclusão digital dos Agentes Comunitários de Saúde (ACS).
} 
O Projeto ocorreu no período de 2009/10, envolveu 14 municípios, e sua ação pedagógica básica constou de um Curso de Introdução à Informática e da Oficina on-line de ALFIN, para os Agentes Comunitários de Saúde (ACS).

\title{
Concepção de alfabetização informacional
}

O conceito de alfabetização faz parte do processo civilizatório e, há muito tempo, está presente nas diferentes políticas de educação, da América Latina e do Brasil. Um dos seus maiores representantes é o brasileiro Paulo Freire, (1983, p.1), que entende o ato de alfabetizar como,

\begin{abstract}
[...] um processo que envolve uma compreensão crítica do ato de ler, que não se esgota na decodificação pura da palavra escrita ou da linguagem escrita, mas que se antecipa e se alonga na inteligência do mundo. [...] Linguagem e realidade se prendem dinamicamente. A compreensão do texto a ser alcançada por sua leitura crítica implica a percepção das relações entre o texto e o contexto [...].
\end{abstract}

Este processo, portanto, está relacionado à necessidade de uma estrutura discursiva comum, construída a partir da "leitura de mundo". A palavra, para Freire, é uma ação dialógica, uma expressão e uma elaboração do mundo, que se faz pela comunicação e colaboração. Isto significa a presença do dialogismo, uma interação mútua e comprometida dos sujeitos, no que versa a igualdade em que cada sujeito possa pronunciar e recriar o seu mundo pelas suas próprias palavras. Se ao sujeito histórico for negado o direito à palavra, suas condições objetivas de enfrentar o mundo com autonomia e liberdade serão cassadas. O diálogo, então, se configura como um potente instrumento de mediação para a formação humana.

Para Freire, no processo educacional, ensinar não é transferir conhecimento, mas criar as possibilidades para a sua própria produção ou a sua construção. É despertar, no educando, a curiosidade e o desejo pela busca do conhecimento que trará, para o processo de aprendizagem, outras vozes indispensáveis, além de sua própria. Esta posição curiosa do educando, e que não deveria ser submissa aos ditames do ensino, se for bem trabalhada e incentivada, dará suporte à formação do seu senso crítico, isto é, a sua leitura crítica do mundo (Freire, 1986).

Considerando que as condições sociais são históricas, a emergência de cidadãos protagonistas, conscientes e criticamente comprometidos com a construção de espaços de aprendizagem que lhes possibilitem autonomia, pressupõe a compreensão da educação como processo comunicacional.

No entender de Jurgen Habermas, este processo é

[...] a forma de interação social em que os planos de ação dos diversos atores ficam coordenados pelo intercâmbio de atos comunicativos, fazendo para isto a utilização da linguagem (ou das correspondentes manifestações extraverbais) orientada ao entendimento. (Habermas, 2001, p.418)

Segundo o autor, torna-se necessária a construção de uma nova racionalidade, definida como 'racionalidade comunicativa', em que, através da comunicação que os sujeitos estabelecem entre si, construam-se interações sociais considerando-se: o mundo objetivo das coisas, o mundo social das normas e instituições, e o mundo subjetivo das vivências e dos sentimentos.

Assim,

[...] enquanto falante e ouvinte se entendem frontalmente acerca de algo num mundo, eles movem-se dentro de horizontes do seu mundo de vida comum [...] O mundo de vida forma um horizonte e ao mesmo tempo oferece uma quantidade de evidências culturais das quais os participantes no ato de comunicar, nos seus esforços de interpretações retiram padrões de interpretações consentidas. (Habermas, 1990, p.278-9) 
Diferentes sujeitos se reúnem livremente em grupos interdisciplinares e multiculturais, em que todos participam democraticamente das discussões, argumentam, justificam e problematizam sua validade, expressam atitudes, sentimentos e desejos referentes à sua subjetividade, orientados por atos regulativos construídos coletivamente.

A interação, portanto, é construída como pretensões de validade (verdade, legitimidade e veracidade); os sujeitos coordenam suas ações, orientando-se segundo normas sociais, construindo um consenso valorativo, um acordo alcançado através da comunicação, com base nestas pretensões de validade (Habermas, 2001).

[Essencialmente], um acordo que fundamente e oriente o dialogo como necessidade inerente à condição humana e alimente o mundo da vida como um lugar transcendental, no qual falante e ouvinte vão ao encontro um do outro. (Habermas, 2001, p.179)

Hoje, segundo Lima (2007), em se tratando das possibilidades ligadas às TIC, tais tecnologias aumentam a capacidade de realização dos processos proposicionais, articulados pelo trabalho intelectual. Neste caso, então, a alfabetização ganha outras denominações, como 'Alfabetização Digital', mas nem sempre sob a luz dessa concepção.

No caso do conceito de Alfabetização em Informação e Comunicação (ALFIN), na perspectiva de Cerveró (2006), relaciona-se aos contextos histórico, econômico, cultural e social, que situam os sujeitos sociais, como fazia Paulo Freire com a tecnologia de sua época, em distintos momentos e em países diferentes, cuja necessidade política determinou a sua prática.

Ao estabelecer a relação alfabetização/contexto social, Cerveró, (2006, p.33) afirma que "en la actualidade podemos hablar de alfabetizaciones y analfabetismo en plural, según las capacidades de cada individuo para relacionarse con la información en diferentes códigos, lenguages y contexto". Assim, essa autora desloca a atenção para a necessidade de um modelo de ALFIN múltiplo, num sentido transversal, associado a novas dimensões de suportes, leituras, interpretações e possibilidades de transformação da informação.

Elemento importante do processo de inclusão digital, a Alfabetização Informacional deve, segundo Sorj (2003), cumprir cinco níveis que este considera importante:

1) Existência de infraestrutura física de transmissão ; 2) a disponibilidade de equipamentos, de conexão de acesso ; 3) treinamento no uso do computador e da Internet ; 4) capacitação intelectual e inserção do usuário, produto da profissão, do nível educacional e intelectual e da rede social que determina o aproveitamento efetivo da informação e das necessidades de comunicação pela Internet; 5) a produção e o uso de conteúdos específicos adequados às necessidades dos diversos segmentos da população. (Sorj, 2003, p.63)

Para esse autor, a distinção entre os diferentes níveis de acesso e uso das TIC contribui para desenvolver metodologias de acompanhamento e atuação, pois cada nível é condição de existência do nível superior, enquanto os níveis superiores sempre determinam a utilidade do nível anterior. $\mathrm{A}$ interdependência entre os níveis determina a centralidade da ação educativa. Sorj (2003) observa que o último nível está relacionado a duas questões. A primeira é a existência de conteúdos informacionais de interesse para todos os grupos sociais; e a segunda, está relacionada à capacidade do indivíduo de produzir e disseminar conteúdos.

Tal perspectiva aproxima-se dos estudos de Paulo Freire (1977, p.45), quando compreende que o processo de aprendizagem e a construção social do conhecimento pressupõem que "o sujeito pensante não pode pensar sozinho; não pode pensar sem a co-participação de outros no ato de pensar sobre o objeto. Não há um 'penso', mas um 'pensamos' que estabelece o 'penso' e não o contrário". Assim, a preocupação de Freire com o homem concreto coloca o diálogo como um instrumento importante para a construção de sua autonomia.

A compreensão de um processo de aprendizagem coproduzido colaborativamente e dialogal tem, tanto em Habermas, em Freire, quanto em Sorj, uma proposição que vai além da racionalidade 
instrumental produzida na modernidade. Racionalidade que se constituiu a partir da relação meios-fins, com base na construção de estratégias para a consecução de objetivos, independente dos sujeitos.

Neste sentido, tanto em Habermas, como em Freire e Sorj, a ação comunicativa só é possível enquanto uma ação de compartilhamento e de consensos construídos entre os sujeitos, a partir de suas experiências vivenciadas em um contexto partilhado e negociado com os demais.

Tratando-se de um processo educativo fundado nas TIC, a atitude profissional de estimular a capacidade autônoma do indivíduo em formação é crucial. A relação ação/reflexão/ação é a base para contribuir com o desenvolvimento da consciência do educando. Esta tarefa envolve a reflexão sobre a ação, e deve acontecer concomitantemente à formulação da sua subjetividade, o que sinaliza, para ele, uma oportunidade de compreender o significado que uma certa atividade tem para a sua existência individual e social. É a compreensão do seu estar-no-mundo, como coloca Freire, que expressa, assim, o processo dialógico em que ele está envolvido, por meio das interações verbais das quais ele participa, e que, também, reconhece a sua voz.

\section{Percursos metodológicos}

O caminho traçado para a análise do Projeto de Inclusão Digital dos ACS de Sergipe foi o da abordagem da pesquisa qualitativa centrada no Estudo de Caso, por entendermos a singularidade do objeto - práticas de Alfabetização em Informação e Comunicação (ALFIN), quando do desenvolvimento das estratégias pedagógicas na formação dos ACS. A técnica utilizada foi o Grupo Focal, de avaliação qualitativa, não diretiva, que coleta dados por meio das interações grupais e se caracteriza como um recurso para compreender o processo de constituição das percepções, atitudes e representações sociais de grupos humanos.

A ALFIN, no Projeto de Inclusão Digital dos ACS sergipanos, realizou-se ao final do Curso de Informática Básica, estruturado via Software Livre e ministrado por multiplicadores escolhidos na comunidade, de cada município. Os conteúdos versaram sobre noções básicas de utilização do hardware e do software, a fim de garantir um bom desempenho no processo de Alfabetização Informacional.

A avaliação centrou-se na Oficina de ALFIN por sua capacidade de expressão, também, dos conteúdos do Curso de Informática Básica, pré-requisito da mesma. Esta foi oferecida a distância, durante um período de trinta dias, com carga horária de vinte horas. Os conteúdos foram disponibilizados na página do Projeto ${ }^{8}$, via mediação de tutoria on-line. Sua estrutura foi composta de quatro movimentos: $1^{\circ}$ ) aprendendo a pesquisar-abordando-se os aspectos da informação, como: onde encontrá-la e como saber de sua confiabilidade ou não; $2^{\circ}$ ) aprendendo a escolher - buscou-se demonstrar as formas de refinamento em uma pesquisa na internet; $3^{\circ}$ ) aprendendo a produzir-criaram-se situações concretas de trabalho de produção de conhecimentos e de informaç̧̃̃es; e $4^{\circ}$ ) aprendendo a comunicar - trabalhando-se os conceitos de comunicação colaborativa e o modelo de comunicação todos-todos (Mendonça, 2008), buscou-se demonstrar as possibilidades de utilização de redes sociais e vídeos em suas práticas educativas.

Dentre os sujeitos que participaram, foi selecionada, intencionalmente, uma amostra de dez ACS, entre aqueles que mais se destacaram no desempenho das atividades do Projeto Inclusão Digital. O grupo, portanto, teve uma composição

${ }^{8}$ Disponível em: <http:// www.inclusaodigital.unb.br>. 
heterogênea, com sete mulheres e três homens, na faixa etária entre 19 e 55 anos, e com nível de escolaridade que variou entre o $1^{\circ}$ grau incompleto e o $2^{\circ}$ grau completo.

O Grupo focal, com duração de uma hora e meia em cada sessão, possibilitou o registro do discurso dos ACS e a identificação e análise das seguintes dimensões que constituíram o roteiro que orientou as discussões: as mudanças ou não percebidas pelos sujeitos, após a Oficina de ALFIN, uma vez que através desta os elementos do curso de informática básica também se expressaram; as facilidades e dificuldades no decorrer da Oficina; facilidades e dificuldades na busca de informações éticas e confiáveis em sítios da internet; e o auxílio das TIC no processo de trabalho, com as comunidades por eles atendidas.

\title{
a) Facilidades encontradas pelos ACS na execução das atividades da Oficina
}

\begin{abstract}
Achei as informações com uma linguagem fácil de entender. O que não entendi, procurei na Internet. O que gostei mais foi que os exemplos eram dentro do que fazemos enquanto Agente Comunitário de Saúde. (ACS 1)

Gostei dos exemplos e da forma que as informações foram 'passadas'. Quando vi os exemplos tomei até um susto porque não imaginava que na Oficina teríamos as nossas tarefas como ACS, como exemplo. (ACS 10)
\end{abstract}

As falas dos ACS 1 e 10 confirmam a preocupação do Projeto quanto à educação comunicacional, já que a adequação da linguagem utilizada na elaboração dos conteúdos e atividades, relacionada ao grau de instrução formal dos sujeitos e ao grau de acessibilidade à informação, fortalece o processo de aprendizagem. Reforça a ideia de que os conteúdos fizeram sentido para se iniciar um processo de reflexão dos sujeitos sobre as suas atividades, pois os conteúdos apresentados diziam respeito às práticas profissionais dos ACS, o que os conduziu a buscarem informações daquilo que não se fez claro e, possivelmente, a tomarem novas decisões, no sentido de transformarem a situação em que se encontravam, na busca de autonomia.

A Oficina, ao problematizar o cotidiano dos sujeitos, em uma linguagem adaptada ao contexto cultural dos ACS, pôde auxiliar na compreensão das informações e reforçou o sentimento de pertencimento e valorização do seu trabalho, enquanto importante prática social, no campo da saúde coletiva. Assim, os sujeitos se reconhecem nos contextos sociais em que estão inseridos, propiciando que se percebam a partir de uma outra perspectiva, e possam valorizar as suas práticas sociais.

\section{b) Dificuldades encontradas pelos ACS da Oficina de ALFIN}

Minha maior dificuldade foi saber mexer direito no computador. Depois da Oficina eu não pratiquei muito os conhecimentos passados pelo professor (multiplicador) e acabei esquecendo as informações que ele me passou. (ACS 1)

Fiquei muito interessada desde o início e gostei muito do projeto, mais, como nunca tinha nem chegado perto de um computador, fiquei com muita dificuldade de lembrar dos passos que o professor ensinou para ligar o computador e acessar a internet. (ACS 3)

As falas dos ACS 1 e 3 remetem-nos a refletir sobre a necessidade da prática cotidiana da utilização das TIC, pois, para que a informação seja incorporada ao arcabouço de conhecimentos dos sujeitos, fazse necessária a utilização constante desses conteúdos, a fim de que sejam incorporados no seu cotidiano. Estas falas suscitam também a necessidade de se rever e ampliar a carga horária da Oficina de Informática Básica em Software Livre, em vista de um maior domínio das habilidades de utilização das TIC para continuar o processo de formação, de maneira positiva. 
A Oficina de Informática Básica poderia ter sido melhor se o rapaz (multiplicador) fosse melhor preparado para atender nossas necessidades. Entrei sem saber nada sobre computador e de como usar sabia menos ainda, estava cheia de vontade em aprender, mas logo fiquei desestimulada por que o professor (multiplicador) era muito despreparado, não é que ele não soubesse o que estava ensinando, o problema é que ele não sabia como ensinar, ele atropelava tudo porque alguns já sabiam alguma coisa e outras não sabiam nada, como eu. Quando cheguei na Oficina de ALFIN tive muita dificuldade. (ACS 8)

A fala do ACS 8 corrobora a preocupação com a aquisição de habilidades mínimas de informática e amplia nossa expectativa em relação à preparação e o nível de domínio didático/pedagógico dos multiplicadores das oficinas. Ressaltamos que a seleção dos multiplicadores do Projeto obedeceu ao princípio de territorialidade, também atribuído aos ACS. Essa escolha se justifica porque, residindo na comunidade, o multiplicador teria o conhecimento prévio das matrizes culturais, sociais e informacionais dos ACS, o que facilitaria, em tese, a contextualização das informações às realidades vividas por eles, considerando que os sujeitos aprendem mais facilmente quando os conhecimentos compartilhados são ressignificados, a partir das experiências já vividas pelos envolvidos em ações educativas (Freire, 1977).

Apesar de os multiplicadores não terem sido sujeitos da Oficina de ALFIN, e sim do Projeto maior, o de Inclusão Digital dos ACS, corroboramos com as colocações dos ACS acerca dos limites desses profissionais - com formação básica de nível médio, alguns não detinham um conhecimento amplo da informática e desconheciam as práticas de informação, educação e comunicação. Questão a ser pensada, pois além de conhecer as comunidades, sua cultura, seus problemas e dificuldades, a formação de tutores, orientadores ou multiplicadores para estas ações deve privilegiar, também, metodologia de trabalho com grupos sociais, de informação, educação e comunicação. Os multiplicadores teriam de abordar as temáticas no contexto dos sujeitos, problematizando-as articuladas à prática profissional dos ACS, junto à comunidade, na relação do processo comunicacional todos-todos, de forma plural (Mendonça, 2008).

\title{
c) Dificuldades na busca de informações éticas e confiáveis na internet
}

\begin{abstract}
A Oficina foi muito importante para inserir a gente no mundo da tecnologia. O que é ruim é a gente não ter a continuidade do curso porque o que tivemos até agora não deu conta das nossas necessidades. Acho muito complicado a pesquisa na Internet porque a gente tem que ficar atento para saber se aquela informação é confiável. (ACS 10)
\end{abstract}

Pesquisar no, como é mesmo o nome, no google, sei lá se o nome é esse mesmo (risos envergonhados da ACS) é mais fácil. Mais quando se trata da pesquisa na Biblioteca Virtual de Saúde (BVS) o negócio muda de figura porque achei muito complicado pesquisar nela. Pra achar o que você quer tem apertar um monte de botões. (ACS 4)

A infoinclusão social não acontece somente quando os sujeitos dominam as competências técnicas sobre a máquina e a navegação na internet. É imprescindível que sejam incorporadas habilidades para aprender a aprender, aprender a identificar as informações confiáveis para uma posterior utilização e publicização de forma ética. Apesar do ACS 4 ter afirmado que achou fácil pesquisar no google, apresenta dificuldades em pesquisar informações nas bibliotecas virtuais de saúde. A necessidade de continuidade das Oficinas para que possam, de fato, desenvolver as habilidades e competências de forma efetiva é aspecto recorrente nas falas dos ACS.

Esse dado chama atenção para que, nas próximas ofertas, seja disponibilizado mais tempo nas atividades de modo geral e, em especial, naquelas que envolvam pesquisas nas bibliotecas virtuais de saúde, já que boa parte das informações disponíveis nos sítios recuperados pelos motores de busca, a exemplo do google, não possibilita a validação da informação encontrada.

Sobre a pesquisa nas bibliotecas virtuais de saúde, referida pelo ACS 4, é importante destacar que estas são bancos de dados e, como tal, utilizam-se dos chamados operadores de busca, tais como o: 
,,+- e/ou outros. Estes comandos dizem a um sistema de bases de dados como as palavras da expressão da pesquisa se relacionam umas com as outras, permitindo o refinamento da busca.

Tais conhecimentos foram trabalhados na oficina de ALFIN, porém, destacamos que as bibliotecas virtuais são estruturadas para a utilização de pesquisadores, tendo em vista as informações divulgadas serem decorrentes: de pesquisas científicas das principais universidades brasileiras e de outros países, do Ministério da Saúde do Brasil, enfim, das instituições de pesquisa. Esse perfil das bibliotecas virtuais dificulta a pesquisa em banco de dados, por parte dos cidadãos pouco familiarizados com esta prática.

\title{
d) Facilidades na busca de informações éticas e confiáveis
}

\begin{abstract}
Não achei nada difícil porque no curso eu aprendi que devemos procurar sites que sejam
\end{abstract} das universidades, da secretaria de saúde, das bibliotecas de saúde e outras. (ACS 2)

Achei fácil pesquisar no google uma informação de saúde para passar para a minha comunidade, mais achei muito complicado achar informações nas bibliotecas de saúde da internet. (ACS 6)

O ACS 2 informou que, após a Oficina, aprendeu a localizar informações em saúde, em páginas da internet de instituições de saúde. A Oficina de ALFIN, realmente, se preocupou em trabalhar com conhecimentos e informações validadas por instituições confiáveis. Essa realidade impacta positivamente nas comunidades por eles atendidas, visto que a informação publicizada é atual, segura e validada por pesquisadores. As falas desses ACS remetem não só ao desempenho da habilidade de aprender a buscar informações nos sítios oficiais, mas à centralidade do ato de aprender. A relação dialógica no processo de aprendizagem não significa somente passar as informações tanto do multiplicador para ele (falas anteriores), quanto dele para a sua comunidade. A fala do ACS 6 suscita a percepção tanto de "aprender" como de "ensinar a aprender", porém não problematizadas.

\section{e) Como as tecnologias auxiliam no processo de trabalho dos ACS com as comunidades}

\begin{abstract}
Semana passada passei um vídeo sobre cigarro para a minha comunidade. Eles ficaram impressionados com o pulmão preto pelo cigarro. Achei que eles se impressionaram mais do que se eu falasse do mal que o cigarro faz. Gostei tanto que estou procurando um vídeo pra falar sobre drogas porque tem muitos jovens que fumam maconha por aqui. (ACS 7)
\end{abstract}

No curso eu aprendi que eu posso fazer um folheto pra distribui nas visitas domiciliares. Gostei porque às vezes falta folheto e eu fico sem ter o que mostrar pra pessoas. Pedi pra minha coordenadora deixar imprimir na impressora do posto de saúde. (ACS 3)

Depois que fiz a oficina e aprendi como usar os recursos do computador e da internet, não consigo nem me lembrar de como eu era antes porque tudo isso facilitou muito a minha vida como ACS. Embora eu não tenha computador em casa, quando preciso vou a uma lan house ou no telecentro e pesquiso, como nem sempre posso imprimir, copio a informação em um caderno e depois levo para as famílias que visito. Eu me sinto incluída digitalmente porque hoje eu já faço uso do computador e da internet para melhorar minha vida profissional. (ACS 9)

A importância de um projeto de infoinclusão social pode ser mensurada na medida em que os infoincluídos efetivamente utilizem os conhecimentos adquiridos em seu cotidiano e, em especial, em sua formação/prática profissional. As falas destes ACS traduzem que a Oficina possibilitou o domínio de competências que foram além das simples aquisição de habilidades tecnológicas, demonstrando o domínio de conhecimento e autonomia suficiente para a resolução de problemas, a partir da construção de estratégias alternativas para a melhoria de suas atividades. 
A mudança de percepção nesta relação se processa na "problematização de uma realidade concreta e [em suas] contradições [e] implica que haja uma apropriação do contexto vivido pelos indivíduos, ou seja, uma inserção nele" (Freire, 1977, p.60). Significa reconhecer o interagir, que é mais que simplesmente enviar e responder mensagens, entender emissão e recepção como espaços recursivos, já que emissor e o receptor passam a fazer parte de um processo de relações interligadas pelos diálogos.

Perceber e avaliar os resultados e o impacto do uso destes conteúdos nas famílias sob suas responsabilidades e, sobretudo, produzir novos materiais a partir das pesquisas para utilização em sua prática de ACS, expressam a dialogicidade colocada por Freire. Este constitui um passo importante no processo de infoinclusão social, baseado na construção da autonomia mediada pelas TIC. Desse modo, ampliam-se as possibilidades de construção, reconstrução e aperfeiçoamento das práticas comunicativas, tornando-as mais eficientes no contato do ACS com os sujeitos por ele assistidos e da realidade em que elaboram.

\title{
f) Mudanças ou não percebidas por eles após a Oficina de ALFIN
}

\begin{abstract}
Comecei a perceber que a internet não serve apenas para mandar e-mail, deixar mensagens no orkut, ela serve também pra eu me preparar melhor para o meu trabalho. Agora sei que posso pesquisar um vídeo de saúde no youtube. As possibilidades que a internet pode me dar são muito importantes para a minha vida. (ACS 8)
\end{abstract}

Descobri que posso continuar estudando e conseguindo conhecimento sem precisar do professor o tempo todo. Isso é muito bom. Mas, ainda tenho muita dificuldade porque não pratico muito, mais sempre que posso vou na lan house e acesso o que está lá no site do projeto de inclusão digital. (ACS 5)

A percepção ampliada do próprio (re)conhecimento da realidade é uma conquista dos sujeitos aprendizes. As práticas de infoinclusão social devem ter, neste ponto de chegada, um de seus objetivos, especialmente aqueles referentes à avaliação, durante e após sua formação, não se restringindo apenas às avaliações cognitivas e/ou referentes ao aprendido enquanto comandos e técnicas, apesar de estes serem pré-requisitos importantes para o desenvolvimento cognitivo na ALFIN. Entretanto, o que muda na visão dos sujeitos aprendizes é a concepção de alfabetização digital.

O modelo de comunicação todos-todos é percebido no processo de ALFIN como algo positivo, relativizando a relação um-todos, comum no processo de aprendizagem formal e nos meios de comunicação de massa. Por isso, as políticas e os programas de ALFIN que propõem ações de formação, nesta concepção de aprender, devem ter continuidade.

É importante que as políticas orientem, incentivem e financiem os diversos setores do serviço público na construção de programas de formação continuada que atualizem seus colaboradores e prepare-os melhor para responderem às novas demandas sociais. As falas comprovam que ao oferecerem programas de infoinclusão social, o Estado e as instâncias públicas devem estar preparados para atenderem aos novos incluídos, agora com novas necessidades, novos objetivos e novas demandas por formação e especialização, portanto, com mais validade científica.

\section{Considerações finais}

O decorrer da investigação deixou claro que o processo de infoinclusão social é muito mais complexo do que imaginávamos, no início das ações do Projeto. Embora iniciativas como as do 'Projeto de Inclusão Digital dos Agentes Comunitários de Sergipe' venham sendo executadas, com sucesso, em diversos lugares no país, precisamos de políticas rigorosas e contínuas que possam transformar de fato o processo de infoinclusão social do cidadão em agir comunicativo.

A inserção das TIC no processo de construção de uma razão comunicativa pressupõe um exercício de compreensão do papel, das circunstâncias e do sentido prático das TIC, no cotidiano dos sujeitos. 
Retomando Freire, podemos afirmar que o compromisso pedagógico e a inserção das TIC no cotidiano dos ACS devem partir de uma compreensão da leitura de mundo destes sujeitos e do lugar das TIC na construção significativa do cotidiano.

Com base nas falas dos Agentes, propomos que as ações de infoinclusão social devem - partindo dos saberes pré-teóricos, que orientam o sentido e o significado das TIC no cotidiano sociocultural e sociotécnico dos mesmos - incentivar e desenvolver redes de diálogo autônomas, interativas e colaborativas entre estes ACS, muito além da mera utilização da tecnologia.

A concepção de infoinclusão social proposta como política de governo deve ser incorporada à prática cotidiana dos sujeitos, nas práticas socioculturais das quais participam na sociedade. Deve, também, garantir a democratização do acesso à internet, via banda larga, e a oferta de espaços gratuitos de acesso, assim como a construção de espaços virtuais de cidadania, tais como o governo eletrônico, entre outros, e considerar, em seus fundamentos, o mundo vivido e o agir comunicativo como norteadores na construção da autonomia e libertação dos sujeitos. Dessa forma, não cabem mais ações/ projetos no campo da infoinclusão social que enfatizem apenas o aspecto objetivo da ação educativa, isto é, que considerem suficientes disponibilizar aparatos tecnológicos para os indivíduos, desconsiderando o papel da razão comunicativa na efetivação de uma educação libertadora, com base na objetivação de uma prática dialógica, consensual e colaborativa dos sujeitos partícipes desta ação e nas relações aí estabelecidas. Só, assim, as TIC poderiam contribuir para a compreensão do próprio mundo da vida.

\section{Colaboradores}

Os autores Pablo Boaventura Sales Paixão, Valéria Pinto Freire, Maria de Fátima Monte Lima, Ronaldo Nunes Linhares, Ana Valéria Machado Mendonça e Maria Fátima Sousa participaram, igualmente, de todas as etapas de elaboração do manuscrito.

\section{Referências}

BRASIL. Ministério da Ciência e Tecnologia. Sociedade da informação no Brasil: livro verde. Brasília: Ministério da Ciência e Tecnologia, 2000.

CERVERÓ, A.C. Alfabetización en información y lectura en los nuevos entornos educativos. In: SIMEÃO, E.; MIRANDA, A. (Orgs.). Alfabetização digital e acesso ao conhecimento. Brasília: UnB/CID, 2006. p.29-40.

FREIRE, P. A importância do ato de ler. São Paulo: Cortez, 1986.

A importância do ato de ler. In: A importância do ato de ler: em três textos que se completam. 3.ed. São Paulo: Autores Associados, Cortez, 1983. p.102-15.

Educação e mudança. Rio de Janeiro: Paz e Terra, 1979.

Extensão ou comunicação? 12.ed. Rio de Janeiro: Paz e Terra, 1977.

HABERMAS, J. Teoría de la acción comunicativa 1: racionalidad de la acción y racionalización social. 4.ed. Madrid: Taurus, 2001. v.1-2.

O discurso filosófico. Rio de Janeiro: Zahar, 1990.

LIMA, F.M.L. No fio da esperança: políticas públicas de comunicação e tecnologias da informação e da comunicação. Maceió: Edufal, 2007.

MENDONÇA, A.V.M. Informação e comunicação para inclusão digital: análise do programa GESAC: Governo Eletrônico Serviço de Atendimento ao Cidadão. Brasília: UnB/CID, 2008.

SORJ, B. Brasil@povo.com: a luta contra a desigualdade na sociedade de informação. Rio de Janeiro: Unesco, Zahar, 2003. 
Apresentam-se os resultados iniciais do projeto de Inclusão Digital de agentes comunitários de Saúde (ACS) de Sergipe, Brasil, quando da realização das práticas de alfabetização em Informação e Comunicação (ALFIN), por meio de Oficinas desenvolvidas como estratégia de aproximação entre os ACS de Sergipe e as Tecnologias de Informação e Comunicação (TIC). Identificam-se caminhos efetivos de infoinclusão social, fundamentando-se na Teoria da Ação Comunicativa de Habermas e nos estudos de Paulo Freire. Utiliza-se a abordagem de pesquisa qualitativa e a tipologia do Estudo de Caso e do Grupo Focal para o esquadrinhamento das práticas de ALFIN a distância.

Palavras-chave: Educação. Comunicação. Saúde. Alfabetização digital. Inclusão social.

The practice of literacy in Health Information and Communication: the opinion of the community health agents about the Digital Inclusion project in Sergipe, Brazil

This article presents the initial results of the Project of Digital Inclusion of Community Health Agents (CHA) of Sergipe, Northeastern Brazil, when they carried out the practice of literacy in Information and Communication. This happened through workshops developed as a strategy for putting the CHA of Sergipe in contact with the Information and Communication Technologies (ICT). Effective ways of social infoinclusion are identified, based on Habermas' Theory of Communicative Action and on Paulo Freire's thought. The qualitative approach was used, as well as the typology of Case Study and Focus Group for scrutinizing the practices of literacy in Information and Communication, using distance learning.

Keywords: Education. Communication. Health. Digital Literacy. Social inclusion.

La práctica de la Alfabetización en Información y Comunicación en Salud: la mirada de los agentes comunitarios de Salud en el proyecto de Inclusión Digital en Sergipe, estado del nordeste de Brasil

Este artículo presenta los primeros resultados del proyecto de Inclusión Digital de agentes comunitarios de salud (ACS) de Sergipe, Brasil, en el ejercicio de la práctica de la alfabetización en Información y Comunicación (ALFIN) a través de talleres desarrollados como una estrategia para aproximar los ACS de Sergipe y las Tecnologías de la Información y la Comunicación (TIC). Busca identificar formas eficaces de inclusión social con base en la Teoría de la Acción Comunicativa de Habermas y en el pensamiento de Paulo Freire. Utiliza el enfoque cualitativo y la tipología de los Estudios de Caso y del Grupo de Enfoque para examinar las prácticas de ALFIN a distancia.

Palabras clave: Educación. Comunicación. Salud. Alfabetización digital. Inclusión social. 